\title{
ENTREVISTA COM CECÍLIA AZEVEDO
}

\section{Roberto Moll* Flávio Limoncic**}

\begin{abstract}
Nesta entrevista que encerra o dossiê Estados Unidos na historiografia brasileira, os organizadores Roberto Moll e Flávio Limoncic conversam com a professora Cecília Azevedo sobre as dificuldades e potencialidades na consolidação do campo da academia brasileira. Cecília possui Licenciatura em História pela Universidade do Estado do Rio de Janeiro, Mestrado em História pela Universidade Federal Fluminense, Doutorado em História Social pela Universidade de São Paulo, PósDoutorado na Universidade Federal de Minas Gerais, na Universidade de Maryland, na Universidade Federal do Rio de Janeiro e na New York University. É Professora aposentada do Departamento de História e do Programa de Pós-Graduação em História da Universidade Federal Fluminense. Desde 1992 participa do NUPEHC - Núcleo de Pesquisas em História Cultural da UFF. Atualmente participa da Rede de Estudos de Estados Unidos, que congrega pesquisadores de diferentes instituições acadêmicas do país e promove encontro científicos periódicos. Tem experiência nos seguintes temas: História dos Estados Unidos, política externa, relações interamericanas, identidade, culturas políticas e imaginário político. Entre as suas principais obras está Em nome da América: os Corpos da Paz no Brasil (Alameda, 2007) e História das Américas: novas perspectivas (Fundação Getúlio Vargas, 2011), organizada com o professor Ronald Raminelli.
\end{abstract}

1- A senhora poderia apresentar uma visão geral dos Estudos Norte-Americanos no Brasil, suas origens e desenvolvimento?

Cecília Azevedo - Os cursos de Pós-Graduação nas universidades públicas brasileiras foram criados nos anos 70. No Rio de Janeiro, o primeiro mestrado foi criado na UFF, em 1971, contando com a contribuição de professores dos EUA, como Stanley Hilton e Richard Graham, na configuração de uma linha de pesquisa em História das Américas. Tais programas refletiam a organização acadêmica então existente e reforçavam tradições disciplinares. Espaços institucionais favorecendo o diálogo interdisciplinar eram raros. A História estava isolada da Antropologia, Literatura, Sociologia e Ciência Política. Cada área tinha sua associação: ANPUH, ANPOCS, ABRALIC...

Uma notável iniciativa em direção contrária foi a criação da ABEA (Associação Brasileira de Estudos Americanos), em 1987, e seu periódico bilíngue, a revista Transit Circle, com a proposta de congregar especialistas de diferentes áreas, favorecendo análises comparativas e uma perspectiva interdisciplinar. Vários professores da UFF, como Marco Antônio Pamplona, Ana Mauad, Paulo Knauss, Sônia Torres e Eduardo Gomes, participaram do esforço. Infelizmente, ao que parece, a ABEA se dissolveu por volta de 2002.

Vivi de perto o desafio da criação da Associação Nacional de Pesquisadores de História Latino-Americana e Caribenha (ANPHLAC), em 1992. Em 1998, a ANPHLAC começou a aceitar trabalhos sobre os EUA, mas só em 2002 sua assembleia decidiu, não sem resistência, mudar o

\footnotetext{
* Doutor em Relações Internacionais (UNESP, UNICAMP, PUC-SP) pela Universidade Estadual Paulista Júlio de Mesquita Filho, Brasil. Professor de História da América II da Universidade Federal Fluminense.

** Doutor em História Social pela Universidade Federal do Rio de Janeiro. Professor Associado da Universidade Federal do Estado do Rio de Janeiro
} 
nome para Associação Nacional de Pesquisadores e Professores de História das Américas. A sigla original foi mantida. No Encontro de 2012, fui eleita presidente, o que penso ter representado a aceitação plena dos estudos de EUA no âmbito da Associação.

Também na Associação de Professores Universitários de História (ANPUH) os estudos norte-americanos têm conquistado maiores espaços. Em 2011, minha grande amiga Mary Junqueira e eu coordenamos o primeiro Simpósio Temático em um Encontro Nacional focado em História dos EUA. Foi um evento marcante, já que desde os tempos do doutorado, na USP, em meados dos anos 90, nos ressentíamos do isolamento e da interlocução rarefeita. Aliás, foi na USP, a partir da generosa acolhida da minha orientadora, Maria Helena Capelato, que conheci Mary Junqueira, minha maior parceira. Nas ANPUHs seguintes, vários STs sinalizaram o crescimento do número de especialistas e do interesse pela História dos EUA.

Mais recentemente, a conformação das Relações Internacionais como campo independente das Ciências Políticas tem estimulado o diálogo entre especialistas em Estados Unidos e relações interamericanas de diferentes áreas. Há que torcer para que as diretrizes e o investimento público em novos Programas de Pós-Graduação em Relações Internacionais não comprometam o desenvolvimento desse campo.

Mas o desenvolvimento que realmente gostaria de destacar, e tendo como referência minha experiência na UFF, foi o I Encontro de Graduandos e Pós-graduandos em História dos Estados Unidos (ENEUA), em 2013, produzido por iniciativa e com o esforço dos alunos. A participação dos alunos de graduação foi muito importante, porque o ensino de História dos EUA enfrenta dificuldades consideráveis nos currículos de licenciatura e bacharelado. Nas disciplinas de História das Américas, a ênfase em América Latina sempre foi a regra, expressando o interesse e as especialidades dos docentes, a falta de material didático em português e a imagem negativa dos EUA no imaginário coletivo e na cultura histórica dominante. O fruto imediato mais importante do Encontro foi a criação da Rede de Estudos dos EUA, responsável por mais cinco edições do ENEUA, sediados, além, da UFF, na UFRJ, UNIRIO, USP e UEL, no Paraná, atraindo interesse de pesquisadores de várias partes do país.

A expansão e sofisticação das pesquisas sobre EUA se expressa hoje na publicação deste dossiê, que coroa o trabalho de professores e pesquisadores desde a década de 80. Na UFF e na PUC-RJ, destaco os estudos sobre liberalismo e republicanismo de Marco Antônio Pamplona e o papel pioneiro de Gerson Moura. A despeito de sua morte prematura, Gerson inspirou trabalhos de vários de nós. Eu mesma, Andre Luiz Vieira Campos e Ana Mauad partimos de seus textos para pensar as assimetrias e contradições nas relações culturais Brasil-EUA. Os trabalhos de Pedro Tota, da PUC-SP, também foram fundamentais para quem seguia essa linha de investigações e ansiava por materiais em português para alimentar seus cursos na universidade. O ingresso de Flávio Limoncic na UNIRIO e de Mary Junqueira na USP, e a publicação de seus trabalhos, estabeleceu uma base acadêmica essencial para formação de novos pesquisadores e a consolidação da Rede de Estudos dos EUA.

Fora do eixo Rio-São Paulo, foi fundamental a atuação de Sidnei Munhoz (UEM), Francisco Ferraz (UEL), Alexandre Busko Valim (UFSC), Arthur Ávila (UFRS) Henrique Alonso Pereira (UFRN), entre outros. Os colegas do Paraná e Santa Catarina estabeleceram uma conexão importantíssima com a Universidade de Brown no Projeto Opening Archives, responsável pela localização, digitalização e indexação de dezenas de milhares de documentos diplomáticos dos EUA sobre o Brasil, sob a coordenação de Sidnei Munhoz e James Green. Vale registrar que brasilianistas de relevo, como Green e Barbara Weinstein, emprestaram imenso apoio acadêmico e 
institucional para viabilizar a pesquisa de historiadores brasileiros que estudaram nos EUA nas últimas décadas. Como presidente da American Historical Association (AHA), Barbara apoiou os esforços de internacionalização da historiografia americana, seguindo ideia expressa por Thomas Bender, David Thelell e Mauricio Tenório sobre a necessária "desestadunização" ou "desparoquialização" da História dos EUA.

Com pesquisas em arquivos no Brasil e nos EUA e auxiliados por acervos e bancos de dados digitais, jovens historiadores brasileiros já se colocam como interlocutores plenos no debate historiográfico sobre os EUA.

\section{2 - Ainda assim, e apesar da importância histórica dos Estados Unidos após a Segunda Guerra Mundial, a área de Estudos Norte-Americanos continua a atrair relativamente pou- cos historiadores no Brasil. A que a senhora atribui tal fenômeno?}

Cecília Azevedo - É um paradoxo que continuamos a enfrentar.

É importante lembrar que a formação de um especialista em história dos EUA exige um investimento grande. Se crescem as oportunidades de circulação e inserção acadêmica, as exigências de qualificação aumentam na mesma medida. É indispensável, por exemplo, o domínio pleno do inglês. Por outro lado, apesar das pressões pela internacionalização que os Programas de PósGraduação recebem das agências de fomento, a escassez cada vez maior de bolsas e financiamentos estreita as possibilidades dos estudantes, e mesmo de pós-graduados, que almejam estabelecer e manter intercâmbios com pesquisadores e instituições nos EUA. Devemos considerar, também, questões menos tangíveis, relacionadas a incentivos acadêmicos, sociabilidade intelectual e sensibilidade política, pois as escolhas acadêmicas passam também por outra ordem de estímulos, ou falta deles. Apesar da ampla circulação de produtos culturais oriundos dos EUA, a complexidade da sociedade e da cultura dos EUA em boa medida escapa aos seus consumidores daqui, favorecendo a consolidação dos estereótipos correntes sobre o "American way of life" que não convidam à reflexão e, mais do que isso, geram sentimentos de saturação e rejeição. Some-se a isso os efeitos negativos da política externa americana sobre a América Latina desde o século XIX.

O que atraia minha geração no final dos anos 70, em convergência com a luta contra a ditadura militar instaurada com apoio dos EUA, era o estudo das teorias da dependência e do imperialismo econômico. As teorias pós-coloniais e os estudos culturais de sociólogos latino-americanos vieram ampliar esse horizonte no final dos anos 80 , mas, mesmo então, não havia grande preocupação em estudar as dinâmicas internas dos EUA. Fazia sentido explorar o binômio hegemonia/subalternidade, mas não se percebia a importância de pensar os conflitos sociais, políticos e culturais da própria sociedade americana, as disputas em torno do americanismo e as conexões possíveis entre atores e movimentos sociais nas Américas. Ironicamente, estabelecia-se uma convergência entre o imaginário coletivo brasileiro (e latino-americano) e a visão de si cultivada pelo establishment americano acerca dos EUA: um peculiar consenso havia fundado e definido a "América" de uma vez por todas.

É compreensível que uma tal representação política e intelectual dos EUA como pura alteridade e negatividade não desperte entusiasmo em jovens estudantes. É preciso muito trabalho para reverter uma cultura escolar e histórica tão longamente sedimentada. Por isso, é fundamental que deixemos de remeter intenções, projetos e ações de diferentes atores americanos a um núcleo de sentido comum, dado e imutável - o Destino Manifesto, o American way of life, o imperialismo, o sentido de missão, etc. Esses termos referem-se a processos históricos e por isso devem ser 
avaliados segundo contextos e práticas específicas, contraditórias.

3 - Quais são, então, os caminhos para despertar o interesse sobre os EUA entre os estudantes?

Cecília Azevedo - Acredito ser essencial expor os alunos ao maior contato possível com a História dos EUA nas disciplinas obrigatórias de História das Américas e através da oferta de disciplinas temáticas ou instrumentais, estimular participação em atividades de laboratórios, projetos coletivos e, certamente, introduzi-los na pesquisa através da Iniciação Científica. Os interesses nessa altura da formação acadêmica são muitos, mas genéricos. A IC é uma oportunidade para um mergulho guiado nas artes do nosso oficio. Ao compartilhar o mapeamento de um conjunto documental, a proposição de hipóteses e métodos de tratamento, os bolsistas têm a oportunidade de construir suas próprias indagações e projetar um caminho individual de pesquisa.

Também me parece fundamental manter espaços em fóruns nacionais, como a ANPHLAC e a ANPUH, e continuar a investir na Rede de Estudos dos Estados Unidos, com dinâmicas locais e a realização de ENEUAs periódicos em diferentes partes do país, de modo a ampliar o debate e o número de especialistas, consolidar laços institucionais e pessoais. A circulação dos resultados das pesquisas precisa ser também incrementada, para além dos Anais eletrônicos, através de publicações como este dossiê, livros, sites e outras plataformas digitais.

O contato direto com reconhecidos especialistas em EUA em eventos internacionais sempre gera entusiasmo, além de abrir caminho para possíveis convênios. Não basta localizar um acervo e reunir recursos para realizar uma viagem de pesquisa aos EUA. É preciso garantir um vínculo institucional. Para estreitar laços acadêmicos com especialistas em história americana nos EUA talvez devamos investir mais em encontros científicos, especialmente as conferências anuais da OAH.

É evidente que para viabilizar tudo isso são necessários recursos das universidades e das agências de fomento e garanti-los não será fácil no futuro próximo.

4 - Talvez a representação política e intelectual negativa sobre a qual a senhora falou nos ajude a entender por que historiadores como Robert Darnton, Lynn Hunt e Hayden White, cujos trabalhos não giram em torno da história dos EUA, tenham se tornado mais conhecidos no Brasil.

Cecília Azevedo - Os historiadores citados foram muito importantes no boom do chamado "linguistic turn" e mais especificamente da História Cultural que nos alcançou no final dos anos 80 e início dos 90. Não se pode desconhecer a contribuição deles para o debate, seu relevo na historiografia americana e sua influência na formação de muitos historiadores brasileiros, inclusive na minha própria. Mas o fato de terem sido traduzidos para o português e terem, inclusive, visitado o Brasil, como Hayden White, revela o peso maior que a Teoria da História e a história europeia especialidade tanto de Lynn Hunt quanto de Robert Darnton - têm na academia brasileira.

O que causa espanto não é o fato de suas obras terem sido traduzidas, mas que grandes historiadores americanos, centrais para a compreensão não só da história dos EUA, mas da prática historiográfica orientada pelas mais diferentes proposições teóricas, não terem merecido atenção. É uma lástima, porque o universo historiográfico americano é dinâmico, descomunal em tamanho e diversidade, com subcampos cronológicos e temáticos impulsionados por associações 
específicas, para além da AHA e da Organization of American Historians (OAH). Os alunos da graduação são especialmente prejudicados pela dificuldade de acesso a textos fundamentais sobre história social, política e cultural, a temas clássicos, como a Revolução Americana, expansão para o oeste, Guerra Civil, Reconstrução, progressivismo, liberalismo, direitos civis, movimento sindical, formação do Estado, etc, assim como a autores com perspectivas tão diversas como Charles Beard, Bernard Baylin, Gordon Wood, Daniel Boorstin, Richard Hosfstadter, Louis Hartz, C. Vann Woodward, Ira Katznelson, Michael Kammen, Linda Kerber, Richard Slotkin, Tomas Bender, Gary Gerstle, William Novak, só para citar alguns de diferentes gerações. Na maior parte das vezes, resta aos alunos acesso indireto a essa historiografia através de manuais e artigos. Acabam, portanto, conhecendo de modo parcial e insuficiente os notáveis avanços que a historiografia americana tem feito, desconstruindo narrativas clássicas da nação, apostando em análises que cruzam gênero, raça e classe, em articulações mais complexas entre Estado e sociedade, o local e o global, a política interna e a política externa.

O que vemos às vezes é o esforço de professores na tradução de textos para suprir necessidades imediatas dos seus cursos, buscando posteriormente sua publicação. Foi o caso de quatro ensaios de Frederick Turner, pai da tese da fronteira, que anima todo um campo de estudos e discussões sobre relações entre história, geografia e cultura, além dos significados simbólicos e materiais da fronteira na história americana. Lançada em 1893, precisamos de mais de um século para ver esta tese traduzida para o português.

5 - A escravidão é tema clássico das historiografias brasileira e americana. Talvez por isso, Eugene Genovese, Paul Lovejoy e Ira Berlin sejam exceção a essa regra geral. Que outros temas poderiam seguir o mesmo caminho?

Cecília Azevedo - As lutas no pós-abolição, conectando diferentes projetos de cidadania e inserção dos libertos nas Américas. Um bom exemplo é o livro mais recente de Martha Abreu, Da senzala aos palcos: Canções escravas e racismo nas Américas, 1870-1930, que analisa a emergência e difusão das chamadas canções escravas no mercado cultural em diferentes pontos do Atlântico Negro, conforme concebido por Paul Giroy. Martha persegue o tempo todo a dimensão transnacional das relações raciais nas Américas através dos significados sociais e políticos associados à música negra nos teatros de revista, circo e na nascente indústria fonográfica, evidenciando que o mundo das artes e do entretenimento, associado aos projetos de modernidade/modernização, foi marcado desde então pela transnacionalidade.

Na mesma linha, é gratificante verificar no último dossiê da Revista da ANPHLAC a publicação de trabalhos como o de Barbara Machado, cujo título expressa bem esse paradigma: "O pensamento feminista "amefricano" e a ideia de articulação entre gênero, classe, raça e sexualidade: Ferramentas de análise para a história das sociedades americanas”.

O investimento na pesquisa de empreendimentos artísticos, intelectuais, educacionais, religiosos, empresariais, militares, etc, conectando indivíduos e grupos diversos através das fronteiras nacionais, mais do que olhares cruzados ou zonas de contato, permite visualizar estruturas de poder, imaginários, linguagens, formas de ação, culturas políticas constituídas e compartilhadas de modo transnacional. Por isso, considero que podemos falar em projetos conservadores, liberais ou de esquerda americanos no sentido continental.

6 - O cinema americano talvez seja o grande arquiteto da consciência histórica que os 
brasileiros têm dos Estados Unidos. Como a senhora vê tal fenômeno?

Cecília Azevedo - Se o século XX foi o século americano, o cinema, que nasceu nas suas primeiras décadas, teve muito a ver com isso. Hollywood tem sido um veículo extraordinariamente potente da cultura popular americana, forjando um sentido para sua história e seu lugar no mundo. Os recursos crescentes da narrativa fílmica servem como um poderoso instrumento, não de justificação explícita da ordem, mas de produção de reconhecimento e engajamento. O cinema coloca em ação referências centrais do imaginário e da experiência social, funcionando como um espaço de reelaboração permanente dos conflitos e traumas da sociedade americana. De David Griffith a Spike Lee, dos westerns de John Ford aos filmes contraculturais sobre Guerra do Vietnã, de Taxi Driver à Guerra na estrelas, o cinema permite acessar uma intensa disputa pela narrativa dominante da nação, incorporando, quando necessário, discursos e identidades minoritárias, invocando sonhos e ideais, mas também ironizando mitos.

Nem sempre é possível, especialmente para um público não americano, compreender codificações mais ou menos sutis dos complexos antagonismos que estruturam a identidade americana. Mas justamente por isso é importante que o cinema seja eleito como tema de cursos, especialmente de graduação. Sempre fui muito feliz quando ofereci cursos instrumentais sobre Cinema e História, focando naturalmente no cinema americano. É importante apresentar o cinema como arte e linguagem que articula memórias sociais, conflitos políticos e proposições estéticas de um determinado contexto histórico. É preciso historicizar Hollywood, pensar como uma indústria que nunca foi estatal pôde metaforizar em sua própria lógica produtiva a organização social dos EUA. É preciso, também, analisar as formas de recepção locais, dado que são indícios relevantes para se avaliar mudanças nas percepções dos EUA ao longo do tempo. Por conta disso, o que significa ser americano no mundo é uma pergunta cada vez mais difícil de responder.

Não só o cinema, mas também outros segmentos da indústria cultural, como quadrinhos e jogos eletrônicos, têm explorado de forma crescente temas e eventos históricos, ampliando sua influência no modo como as sociedades lidam com a relação passado-presente-futuro. Abrem-se muitos desafios teóricos e metodológicos para o historiador, ao mesmo tempo em que os universos culturais se transformam e interpenetram. Não devemos nos contrapor, por vaidade corporativa, ao escrutínio da história promovido pelo cinema, mas buscar decompor e analisar os elementos que o constituem.

\section{7 - Como a senhora pensa sua própria contribuição para área de Estudos Norte-America- nos no Brasil?}

Cecília Azevedo - Em primeiro lugar, me orgulho de ter contribuído, no Curso de Graduação em História da UFF, para a formação de professores para o ensino médio e fundamental. Já há uma geração espetacular de docentes com condições de combater estereótipos e apresentar os EUA como uma sociedade complexa, marcada pela diversidade étnica, cultural e ideológica e por intensas lutas sociais e políticas.

Após finalizar o doutorado, pude incluir os EUA nos projetos sobre Culturas Políticas do NUPEHC e no setor temático de História Contemporânea II do PPGH. Os cursos na Graduação, no Lato-Sensu e no PPGH me permitiram reunir estudantes que constituiriam a base para um trabalho coletivo que redundou no I Encontro de Graduandos e Pós-Graduandos, já mencionado, transformando em realidade o desejo de criar a Rede de Estudos dos EUA em âmbito local e 
depois nacional.

Registro, portanto, que nunca estive sozinha. Tive ao meu lado colegas e alunos da UFF e de outras Universidades.

O diálogo e o apoio de Mary Junqueira foram fundamentais para acreditar que poderia pensar as relações do Brasil com os EUA articulando aspectos simbólicos e materiais, imaginários sociais, projetos políticos e percursos individuais. Aqui no Rio de Janeiro, Flavio Limoncic, Tatiana Poggi, Thaddeus Blanchette, Roberto Moll e Rodrigo Farias de Sousa têm sustentado com grande competência e entusiasmo as bases institucionais e os trabalhos da Rede na UFF, UNIRIO e UFRJ. É motivo de imensa felicidade assistir uma nova geração fazer avançar os estudos de Estados Unidos em várias universidades do país, inclusive as mais distantes, como é o caso de Alexandre Guilherme da Cruz Alves Junior, na Universidade Federal do Amapá e o de Flavio Trovão, na Universidade Federal de Mato Grosso. Como é natural e desejável, minhas experiências de ensino e pesquisa já foram ultrapassadas em muito por eles, o que me permite agora usufruir plenamente da aposentaria. 